\title{
Sophomore Students' Conceptions of and Approaches to Learning with Reference to College of Social and Behavioral Sciences at Arba Minch University
}

\author{
Abate Demissie Gedamu* \\ College of Social Sciences and Humanities, Department of English, Arba Minch University \\ P.o.box 021, Arba Minch, Ethiopia \\ Getu Lema Shewangezaw \\ College of Social Sciences and Humanities, Department of Geography \& Environmental Studies, Arba \\ Minch University \\ Tesfaye H. Mariam Gezahegn \\ College of Social Sciences and Humanities, Department of English, Arba Minch University
}

\begin{abstract}
Appropriate conceptions of and approaches to learning are essential for students at all levels of education. To this effect, this study aimed to explore sophomore students' conceptions of and approaches to learning at Arba Minch University, College of Social and Behavioral Sciences. Systematic random sampling technique was employed to select $(\mathrm{N}=106)$ students for the study. In order to gather data from the participants on their conceptions of and approaches to learning, The Approaches and Study Skills Inventory for Students (ASSIST) was used. To answer students' conceptions of learning, independent sample t-test was applied. In order to decide the overriding learning approach they used, Kruskalwallis test was used. Spearman's rank-order correlation was employed to examine the association between students' conceptions of learning and approaches to learning. The results of the study showed the students had both reproductive/surface and transforming/deep conceptions of learning equally. In addition, the study revealed strategic approach to learning was dominant over the other two followed by surface and deep approaches successively in their rank orders. On the basis of the results, it was recommended that teachers should do their best develop their students conception that learning is meaning making and understanding through inquiry based, experimentation, and problemsolving instructions that encourage the qualitative conceptions of learning and deep approach to learning.
\end{abstract}

Keywords: conception; learning; conception of learning; approach to learning

DOI: $10.7176 /$ RHSS/10-7-04

Publication date: April $30^{\text {th }} 2020$

\section{INTRODUCTION}

\subsection{Background and Rationale of the Study}

Higher education institutions provide citizens access and opportunities to advanced education to satisfy the qualified professional needs of a country. Accordingly, the institutions are expected to produce graduates capable of solving societal problems equipped with knowledge, skills and attitude. In line with this, MoE (2010) document underlined the goal of Ethiopian higher education and noted:

The goal is to develop highly qualified, motivated and innovative human resources and produce and transfer advanced and relevant knowledge for socio-economic development and poverty reduction with a view to turning[sic] Ethiopia into a middle-income country by the year 2025(p.9).

In spite of the goal of Ethiopian higher education stipulated in the documented above, studies pointed out that there are dissatisfactions with the quality of graduate performances at their work places (Abebe, 2014; Mulu, 2012; Matheas, 2017; Tekeste, 2006). This may emanate from inappropriate approaches learners employ to their learning though there might be a number of reasons (Hativa, 2000). This made the study on students' approach to learning necessary.

In order to understand students' approach to learning, it is paramount important to examine their conceptions of learning as conceptions are powerful in shaping individuals' approaches to learning (Kawulich, Garner \& Wagner; 2009). Students' approach to learning is the ways in which individuals perceive and process information (Biggs, 2003), and it is significant/ powerful facet which shapes the quality of learning (Dart, Pillay \& Burnett, 2000; Duf, Boyle \& Dunleavy, 2002). Previous empirical works on students' conceptions of and approaches to learning and the association between conceptions of learning and approaches to learning have been reviewed with the aim of looking for felt niches and rationale of the current study. To begin with, Säljö (1979) spotted five categories of conceptions of learning which comprise learning as an increase of knowledge, memorizing, an acquisition of facts or principles, an abstraction of meaning, and an interpretive process to understanding reality. Latter the sixth category which viewed learning as 'changing as a person' was identified (Marton, Dall'Alba \& 
Beaty, 1993). Thus, it has been argued that these six categories could represent most people's conceptions of learning. The six conceptions of learning were dichotomized into 'quantitative' and 'qualitative' (Biggs, 1994).

Concerning students' approaches to learning, the study carried out at College of Education on Turkish and American students showed most Turkish and American students favored deep and strategic approaches to learning as compared to the surface ones (Senemglu, 2011). A couple of local studies were also reviewed on approaches to learning. To this end, Eshetu (2018) conducted a study on the relationship between instructors' approaches to teaching and students' approach to learning and learning outcomes at Debre-Markos University, College of Education and Behavioral Sciences. The participants of the study were 16 teachers and 134 under graduate students. In order to generate data on students' approaches to learning, two factors study process questionnaire was used. The finding revealed that the students employed deep approach more often than surface approach to learning .In the same vein, the study done by Matheas (2017) on randomly selected 382 students at Mizan Tepi University revealed that the majority of the students adopted deep approach to learning followed by surface approach to learning.

In relation to the association between students' conceptions of learning and approaches to learning, studies disclosed that students' quantitative/surface conceptions of learning were closely linked to their surface approach to learning. In contrast, qualitative/deep conceptions of learning were highly related to students' deep approach to learning (Dart, Pillay \& Burnett, 2000; Edmunds \& Richardson, 2009).

On the basis of the reviews made, it seems there is scarcity of studies on Ethiopian students' conceptions of learning. In addition, conception of learning is culture specific (Biggs, 2003). Moreover, approaches to learning are influenced by personal and contextual factors, and institutional values (Biggs, Kember \& Leung, 2001; Biggs, 2003). Furthermore, the relationship is mediated by respective institutions assessment system, teaching methods, and self-concept of the students (Burnett, Pillay \& Dart; 2003). To this effect, the findings of the studies made elsewhere might not reflect Ethiopian university students. Therefore, it seems essential to see if students' conceptions of and approaches to learning in Ethiopian universities are similar to the findings elsewhere or could be colored due to the differences. Hence, this study aims to explore sophomore students' conceptions of and approaches to learning at Arbaminch University in the College of Social and Behavioral Sciences in 2020.

\subsection{Objective of the Study}

This study has both general and specific objectives. The general and specific objectives are provided below independent of each other.

\subsubsection{General Objective}

The general objective of this study is to explore sophomore students' conceptions of and approaches to learning at Arbaminch University in the College of Social and Behavioral Sciences.

\subsubsection{Specific Objectives}

1. To explore sophomore students' conceptions of learning in the College of Social and Behavioral Sciences,

2. To identify the learning approaches of sophomore students in the College of Social and Behavioral Sciences, and

3. To examine the association between sophomore students' conceptions of learning and approaches to learning in the College of Social and Behavioral Sciences.

\section{RESEARCH METHODOLOGY}

\subsection{Research Design}

The general objective of this study is to explore sophomore students' conceptions of and approaches to learning with reference to College of Social and Behavioral Sciences at Arba Minch University in 2020. To address the objective of the study, cross-sectional descriptive survey design was adopted since the purpose of the study is mainly to describe the incident at certain point in time. The Approaches and Study Skills Inventory for Students (ASSIST) was used to generate quantitative data on participants' conceptions of and approaches to learning.

\subsection{Participants of the Study}

Sophomore students in the College of Social and Behavioral Sciences at Arbaminch University were the population of this study. At the time of the study, the total number of students in the two colleges was 632. Among this population, $20 \%$ of them were selected through systematic random sampling technique. This constituted 126 students to be addressed through ASSIST. However, 20 students have not filled the questionnaire properly and this made the response rate $84 \%$.

\subsection{Data Collection Instrument}

This study explored sophomore students' conceptions of and approaches to learning, and the association between students' conceptions of learning and approaches to learning in the College of Social and Behavioral Sciences at Arbaminch University. To address these objectives, (ASSIST) which was developed by Entwistle (2000) was used. 
This inventory or ASSIST consists of 58 items with two parts. The first part comprised of six-items with two subscales (qualitative and quantitative conceptions) of learning. The first three in combination comprised reproducing conception of learning while the remaining three cover 'transforming' conception of learning. The second part consists of 52 items which measure students' approaches to learning with three dimensions: deep, strategic, and surface approaches. The deep approach constitutes 16 items with four sub-scales. Similarly, the surface approach is comprised of 16 items with four sub-scales. The strategic approach, on the other hand, is made up of 20 items with five sub-scales. All items of ASSIST are prepared on a five-point Likert scale with values of $5=$ agree, $4=$ agree somewhat, 3 = unsure, $2=$ disagree somewhat and $1=$ disagree.

In order to make filling ASSIST easy and clear, it was translated into Amharic language, an official federal state language. Its internal consistency has been presented below.

\subsection{Reliability and Validity of Tools}

The English version of the questionnaire (ASSIST) was translated into Amharic by translation expert at Arbaminch University, English Department. The translated Amharic version was translated back to English to check the consistency between the original statement and the statement of the Amharic version. Both versions were checked for compatibility by the experts. Then, the Amharic and English versions were administered to sophomore students in different departments than the participants of the actual study within two weeks time interval. Finally, the correlation between the Amharic and English versions was checked for compatibility to claim the Amharic version of ASSIST for use. There was significant and strong positive correlation between the Amharic and English versions $(\mathrm{r}=0.84, \mathrm{p}<.01)$. This implies that the Amharic version of ASSIST could be used to generate data on students' conceptions of and approach to learning. The internal consistency of the Amharic version of ASSIST was also checked as indicated below in table 1. The tool showed Cronbach's Alpha values ranged from .83 to .86 that implied high internal consistency reliability.

Table 1 The internal consistency reliability scores of ASSIST

\begin{tabular}{lllc}
\hline \hline Scales/dimensions & Mean & Std. deviation & Cronbach Alpha \\
\hline \hline Deep approach & $\mathbf{3 . 4 7}$ &. $\mathbf{7 7}$ & $\mathbf{. 8 3}$ \\
Seeking meaning & 3.39 & .80 & .84 \\
Relating ideas & 3.39 & .85 & .83 \\
Use of evidence & 3.67 & .91 & .84 \\
Interest in ideas & 3.39 & .86 & .84 \\
Surface approach & $\mathbf{3 . 6 5}$ & $\mathbf{. 4 7}$ & $\mathbf{. 8 6}$ \\
Lack of relatedness & 3.47 & .68 & .86 \\
Lack of purpose & 3.67 & .65 & .86 \\
Syllabus boundness & 3.75 & .62 & .86 \\
Fear of failure & 3.70 & .65 & .85 \\
Strategic approach & $\mathbf{3 . 8 4}$ & $\mathbf{. 4 3}$ & $\mathbf{. 8 4}$ \\
Organized Study & 3.77 & .62 & .85 \\
Time management & 3.88 & .59 & .85 \\
Achieving & 4.07 & .61 & .84 \\
Alertness to assessment demands & 3.63 & .67 & .85 \\
Monitoring effectiveness & 3.53 & .97 & .84 \\
Conceptions & & & .85 \\
Reproducing conception & 4.17 & .49 & .86 \\
Transforming conception & 4.21 & .63 & .85 \\
\hline \hline
\end{tabular}

\subsection{Methods of Data Analysis}

The data obtained through ASSIST was quantified at item level and summed up to come up with the average values for conceptions of learning sub-scales- qualitative and quantitative and approaches to learning. To decide whether the students' conceptions of learning were qualitative or quantitative or both, independent sample t-test was applied as the data was found distributed normally. The second objective of this study was to identify the sophomore students' approaches to learning. In order to decide the dominant learning approach the students' make use of, Kruskal-wallis test was applied as homogeneity-of-variance (Levene's test for the assumption of equal variances) statistic were $(\mathrm{p}<.05)$ for ASSIST and sub-scales. This implied that the variances are not equal to apply parametric one way ANOVA and hence Kruskal-wallis test was used.

To examine the association between sophomore students' conceptions of learning and approaches to learning, Spearman's rank-order correlation was employed as there was no linearity between the data on conceptions of learning and approaches to learning. It should be noted that five percent $(\alpha=0.05)$ level of significance was applied throughout the study. 


\section{Results and discussions of Social and Behavioral Science Students' Conceptions of and Approaches to Learning \\ 3.1 Students' Conceptions of Learning}

The first objective of the study was to explore students' conceptions of learning with specific reference to second year Social and Behavioral Sciences at Arbaminch University. To this end, t-test result is provided below.

Table 2 independent t-test result on students' conception of learning

\begin{tabular}{lccccc}
\hline \hline Scale/Sub-scale & $\mathbf{N}$ & Mean & $\mathbf{t}$ & $\mathbf{d f}$ & $\mathbf{p}$ \\
\hline \hline Reproducing Conception & 106 & 4.14 & -.17 & 210 & .866 \\
Transforming Conception & 106 & 4.16 & & & \\
\hline \hline
\end{tabular}

The two-tailed independent sample t-test table 2 demonstrated there is no statistically significant mean difference between students' reproducing and transforming conceptions of learning at 0.05 level $(t=-.17$, $\mathrm{df}=210, \mathrm{p}=.87$ ) since $\mathrm{p}>0.05$. This shows that both conceptions exist equally among second year students of Social and Behavioral Sciences at Arbaminch University. The current finding corroborates with the 'quantitative' and 'qualitative' dichotomous perspectives of learning conceptions made by Biggs (1994). Accordingly, the quantitative view of learning is concerned with the acquisition and accumulation of knowledge while the qualitative view of learning is about understanding and meaning-making through connecting new knowledge with the prior one (Biggs ,1994). Divergently, the study done by Purdie and Hattie (2002) indicated little claim for the existence of the two qualitatively different conceptions that are referred surface and deep conceptions. Nevertheless, it should be noted that conceptions of learning could be influenced by learning experiences of different subject disciplines (Biggs, Kember \& Leung, 2001) and culture (Biggs, 2003).

\subsection{Students' Approaches to Learning}

The second objective of the study was to investigate students' approaches to learning with specific reference to second year Social and Behavioral Sciences at Arbaminch University. The analysis is provided below.

Table 3 Kruskal-wallis Test Statistics

\begin{tabular}{ll}
\hline \hline & Approaches to learning \\
\hline \hline Chi-Square & 13.025 \\
df & 2 \\
Asymp.Sig & .001 \\
\hline \hline
\end{tabular}

A Kruskal-wallis test showed in table 3 above, there is statistically significant differences in pair score between the different approaches to learning $\left(X^{2}(2)=13.025, p=.001\right)$. To know the approaches which the students used dominantly or least, Kruskal-wallis test statistics mean ranks for the three groups were indicated in table 3 below.

Table 4 Mean rank scores

\begin{tabular}{llc}
\hline \hline Sub-scales & N & Mean Rank \\
\hline \hline Deep approach & 106 & 138.79 \\
Surface approach & 106 & 155.83 \\
Strategic approach & 106 & 183.88 \\
\hline \hline
\end{tabular}

The mean ranks for the three groups showed that students with strategic approach (183.88) had the highest score followed by surface approach (155.83) and deep approach (138.79) to learning with the least mean rank. This implies that the students used surface approach to memories the course materials and strategic approach to obtain highest grades. The study done on Turkish and American students at College of Education revealed that most Turkish and American students employed deep and strategic approaches to learning as compared to the surface ones (Senemglu, 2011). Unlike the finding of Senemglu (2011), the current study indicated the students favored strategic and surface approaches to learning. In contrary, the studies carried out by Eshetu (2018) on undergraduate students' approach to learning at Debre-Markos University, College of Education and Behavioral Sciences, and Matheas (2017) at Mizan Tepi University disclosed that the students employed deep approach more often than surface approach to learning. Nonetheless, one should bear in mind that both of these studies used two factors study process questionnaire to generate data on students' approaches to learning.

According to early works, students who adopt surface approach focus on facts and emphasize rote learning and use memorization techniques (Biggs, 2003) with the intention of avoiding failure. Conversely, students who adopt deep approach center on meanings and understanding (Biggs, 2003), and can organize ideas and be able to recall and apply easily the ideas or knowledge they have acquired into practice (Entwistle, McCune \& Walker, 2000). On the other hand, students who adopt strategic/achieving approach to learning apply a deep or surface approach to maximize their grades and excel others through appropriate use of study skills and cue-seeking behavior (Entwistle, McCune \& Walker, 2000; Entwistle \& Peterson, 2004).

Findings on approaches to learning may not be similar at all places and institutions due to the fact that approaches to learning are influenced by personal and contextual factors, and institutional values (Biggs, Kember 
\& Leung, 2001; Biggs, 2003), assessment procedures (Scouller \& Chapman, 1999) and demands of courses (Biggs, Kember \& Leung, 2001). Study showed that deep approach to learning was rarely rewarded by the evaluation system as evaluations mainly assess knowledge for which the use of a surface approach may be enough to be successful (Baeten, Kyndt, Struyven, \& Dochy, 2010). In addition to the nature of classroom assessment, teaching methods of teachers may encourage reproductive form of learning (Gijbels et al., 2005). Therefore, university students could adopt surface and strategic approaches over deep approach in order to obtain good marks and avoid failure.

Although the aim of university education is to promote independent learners who could solve societal problems through developing deep approach to learning (MoE, 2010; Entwistle \& Peterson, 2004), the current study seems to show divergent finding from the stipulated goal of tertiary education. To this effect, the finding revealed that the students favored surface and strategic approaches to learning dominantly.

\subsection{The Relationships between Students' Conceptions of and Approaches to Learning}

The third objective of the study was to examine the relationships between students' conception of and approaches to learning with specific concern on second year students of Social and Behavioral Sciences at Arbaminch University. The analysis is provided below.

Table 5 Correlations between conception and approaches to learning

\begin{tabular}{|c|c|c|c|c|c|}
\hline & 1 & 2 & 3 & 4 & 5 \\
\hline Deep & 1 & & & & \\
\hline Surface & -.056 & 1 & & & \\
\hline Strategic & $.465 * *$ & $.418 * *$ & 1 & & \\
\hline Reproducing & .112 & .140 & $.392 * *$ & 1 & \\
\hline Transforming & .061 & .060 & .128 & $.453 * *$ & 1 \\
\hline
\end{tabular}

**. Correlation is significant at the 0.01 level (2-tailed).

*. Correlation is significant at the 0.05 level (2-tailed).

Spearman's rank-order correlations were run to determine the associations between students' conceptions of and approaches to learning scores. There was positive and significant monotonic correlation between reproducing conception and strategic approach to learning $(\mathrm{r}=0.39, \mathrm{p}<.01)$. The table also showed correlations between approaches to learning scales. Accordingly, the deep approach scale was positively correlated with the strategic approach scale $(\mathrm{r}=0.46 \mathrm{p}<.01)$. Similarly, the surface approach scale was positively correlated with the strategic scale $(\mathrm{r}=0.42, \mathrm{p}<.01)$. Besides, there was positive and statistically significant correlation between the reproducing and the transforming scales $(\mathrm{r}=0.45, \mathrm{p}<.01)$.

The finding of the current study showed that reproducing conception correlated with strategic approach to learning. This finding is harmonious with the early works that students' quantitative/surface conceptions of learning correlated to their surface or strategic approach to learning while qualitative/deep conceptions of learning related to students' deep approach to learning (Dart, Pillay \& Burnett, 2000; Edmunds \& Richardson, 2009).

\section{Conclusions and Recommendations}

The objectives of this study were to explore university students' conceptions of learning, their approaches to learning, and to examine the association between students' conceptions and approaches to learning. To this effect, this study disclosed that the sophomore students had both reproductive/surface and transforming/deep conceptions of learning equally. Concerning their learning approaches, the study showed that most students had strategic approach over the other two followed by surface and deep approaches consecutively in their rank orders. With regards to the association between students' conceptions of and approaches to learning, the result indicated positive and significant relationship between reproducing conception and strategic approach to learning only.

This study recommends that teachers should help their students develop qualitative conception of learning that learning is meaning making and understanding through inquiry based, experimentation, and problem-solving instructions that encourage the qualitative conceptions of learning and deep approach to learning among students. This study was conducted on second year students in the Colleges of Social and Behavioral Sciences at Arbaminch University as a unit of study without making distinction on their domains of studies (disciplines). They might have quite different conceptions of and approaches to learning as functions of their fields of studies or domains of learning. Therefore, future studies on this area should explore if there will be differences on students' conceptions of and approaches to learning due to their major fields of study. In addition, this study was done with self-report student questionnaire only. Future studies should consider the use additional tools on measuring students' conceptions of and approaches to learning for more valid results. Early works underlined that teachers' inappropriate assessment which focuses on surface learning may foster reproductive conceptions of learning and surface approach to learning for which the use of a surface approach suffices to be successful (Dart et al., 2000; Lizzio, Wilson \& Simos, 2002). Thus, future studies should explore assessment procedures and types of 
assessment teachers employ so as to examine the kind of conception and approaches to learning the assessment could produce in Ethiopian Higher Education. This study adopted cross-sectional design and took data at one instance. We recommend longitudinal studies which enhance data collection over different times for more credible outcomes.

\section{Acknowledgements}

We would like to acknowledge Arba Minch University for funding this study. We would also like to thank head of research coordination office at CSSH for his genuine and unreserved facilitation of research fund and timely responses to any query we had. We are also grateful to students who were cooperative and helpful during the data collection.

\section{Conflict of interests}

There is no conflict of interests.

\section{References}

Abebe, R. (2014). Institutionalization of quality assurance in an Ethiopian public university.Master's thesis, University of Tampere, Finland. Available https://tampub.uta.fi/bitstream/handle/10024/96063/gradu07194.pdf?sequence=1

Baeten, M., Kyndt, E., Struyven, K., \& Dochy, F. (2010). Using student-centered learning environments to stimulate deep approaches to learning: Factors encouraging or discouraging their effectiveness. Educational Research Review, 5, 243-260.

Biggs, J. (1994). 'Student Learning Research and Theory: Where Do We Currently Stand?', in G. Gibbs (ed.) Improving Student Learning: Using Research to Improve Student Learning, pp. 1-19. Oxford: Oxford Centre for Staff Development.

Biggs, J., Kember, D. \& Leung, Y. P. (2001). The revised two-factor study process

Questionnaire: R-SPO-2F. British Journal of Educational Psychology, 71, 133-149.

Biggs, J. B. (2003). Teaching for Quality Learning at University. Buckingham: The Society for Research into Higher Education \& Open University Press.

Burnett, P., Pillay, H.\& Dart, B. (2003). The influences of conceptions of learning and learner self-concept on high school students' approaches to learning.

Dart, B., Pillay, H. \& Burnett, P.C. (2000). 'Australian and Filipino Students' Approaches to Learning, Conceptions of Learning, and Learner Self-Concepts: A Cross Cultural Comparison'. Educational Research Journal, 15: 143-66.

Duf, A., Boyle, E.\& Dunleavy, K. (2002). The relationship between personality, approach to learning, emotional intelligence, work attitude and academic performance. In W. C. Smith (Ed.), The7th Annual ELSIN Conference (pp. 141-151).

Entwistle, N. (2000). Approaches and study skills inventory for students (ASSIST). http://www.tla.ed.ac.uk/etl/questionnaires/ASSIST.pdf

Entwistle, N.J., Mc Cune, V., \& Walker, P. (2000). Conceptions, styles and approaches within higher education: Analytic abstractions and everyday experience. In R.J. Sternberg, \& L.F. Zhang (Eds.), Perspectives on cognitive, learning, and thinking styles. New Jersey: Lawrence Erlbaum.

Entwistle, N. \& Peterson, E. (2004). Conceptions of learning and knowledge in higher education: Relationships with study behavior and influences of learning environments. International Journal of Educational Research, 41, 407-428.

Edmunds, R. \& Richardson, T. (2009). Conceptions of learning, approaches to studying and personal development in UK higher education. British Journal of Educational Psychology, 79, 295-309.

Gijbels, D., Watering, G. V. D., Dochy, F., \& Bossche, P. V. D. (2005). The relationship between students' approaches to learning and the assessment of learning outcomes. European Journal of Psychology of Education, $X X(4), 327-341$.

Hativa, N. (2000). Teaching for effective learning in higher education. Dordrecht: Klumer academicpublishers.

Kawulich, B., Garner, M. \& Wagner, C. (2009). Students' Conceptions and Misconceptions of Social Research. Qualitative Psychology Review, $\quad 5 \quad$ 525.(http://www.qualitativesociologyreview.org/ENG/archive_eng.php)

Lizzio, A., Wilson, K. \& Simons, R. (2002). University students' perceptions of the learning environment and academic outcomes: implications for theory and practice. Studies in Higher Education, 27(1), $27-51$.

Marton, F., Dall'Alba, G. \& Beaty, E. (1993) 'Conceptions of Learning'. International Journal of Educational Research, 19, 277-300.

Matheas, S. (2017). Students' conception of learning environment and their approach to learning and its implication on quality education. Educational Research and Reviews, 12(14), 695-703. DOI: 


$$
\text { 10.5897/ERR2017.3258 }
$$

Ministry of Education. (2010). The Federal Democratic Republic of Ethiopia Education Sector Development Program (ESDP) IV: program action plan. Addis Ababa: Ministry of Education.

Mulu, N. (2012). Quality and quality assurance in Ethiopian higher education: critical issues and practical implications. Enschede: Center for Higher Education Policy Studies (CHEPS).

Purdie, N. \& Hattie, J. ( 2002 ). Assessing Students' Conceptions of Learning. Australian Journal of Educational \& Developmental Psychology, 2, 17-32.

Saljo, R. (1979).Learning from the Learner's Perspective. I: Some Common Sense Conceptions. Goteborg, Sweden: University of Goteborg, Institute of Education.

Senemoglu, N. (2011). College of Education Students' Approaches to learning and Study Skills. Education and Science, 36(160), 65-80.

Tekeste, N. (2006). Education in Ethiopia: from crisis to the brink of collapse. Uppsala: Nordiska Afrika institute. 